\title{
PPM PEMBERDAYAAN KESEJAHTERAAN KELUARGA (PKK)
}

\author{
Suprayoga $^{1 *}$, Arini Sulistyowati ${ }^{2}$, Fitra Mardiana ${ }^{3}$ \\ ${ }^{1}$ Fakultas Ekonomi dan Bisnis, Universitas Wijaya Putra \\ ${ }^{2}$ Fakultas Ekonomi dan Bisnis, Universitas Wijaya Putra \\ ${ }^{3}$ Fakultas Ekonomi dan Bisnis, Universitas Wijaya Putra
}

suprayoga@uwp.ac.id, arinisulistyowati@uwp.ac.id, fitramardiana@uwp.ac.id

\begin{abstract}
Abstrak
Pemberdayaan dan Kesejahteraan Keluarga (PKK) adalah program yang dilaksanakan untuk memenuhi kebutuhan dasar untuk terwujudnya kesejahteraan keluarga. Salah satu wilayah yang melaksanakan PKK adalah Kelurahan Babat Jerawat, Kecamatan Pakal, Surabaya. Dalam penyelenggaraan 10 tugas pokok PKK masih terdapat program pokok PKK yang belum terlaksana dengan baik. Tujuan kegiatan ini adalah untuk meningkatkan penerapan program pokok PKK terkait pangan, pendidikan dan ketrampilan serta kelestarian lingkungan hidup. Metode yang dilakukan dalam kegiatan ini berupa penyuluhan, pelatihan dan pendampingan terhadap peran ibu-ibu PKK untuk meningkatkan kebersihan dan kesehatan lingkungan, pelatihan persemian dan pembibitan tanaman dan budidaya lele. Hasil dari kegiatan ini adalah menambah wawasan dan pengalaman bagi ibu-ibu PKK, terciptanya lingkungan yang bersih dan lahan kosong yang ada di sekitar rumah telah dapat dimanfaatkan dengan baik dan produktif seperti adanya bibit tanaman buah, sayur, toga dalam pot dan budidaya lele dalam terpal. Dengan pelaksanaan kegiatan ini secara berkelanjutan dapat berkontribusi dalam memberdayakan keluarga untuk meningkatkan kesejahteraan.
\end{abstract}

Kata kunci: PKK, program pokok PKK, kebersihan lingkungan, budidaya lele.

\section{PENDAHULUAN}

Menurut Peraturan Menteri dalam Negeri Republik Indonesia Nomor 36 tahun 2020, Pemberdayaan dan Kesejahteraan Keluarga (PKK) adalah salah satu lembaga kemasyarakatan Desa/Kelurahan yang mewadahi partisipasi masyarakat dalam bidang pemberdayaan kesejahteraan keluarga yang berada di tingkat Rukun Warga dan Rukun Tetangga atau sebutan lain yang mengkoordinasikan kelompok dasawisma (Permendagri, 2020).
Gerakan (PKK) merupakan gerakan pembangunan masyarakat yang tumbuh dari, oleh, dan untuk masyarakat, untuk mewujudkan Keluarga yang beriman dan bertaqwa kepada Tuhan Yang Maha Esa, berakhlak mulia dan berbudi luhur, sehat, sejahtera, maju dan mandiri, kesetaraan dan keadilan gender, serta kesadaran hukum dan lingkungan (Permendagri, 2020). Penyelenggaraan gerakan PKK secara nasional yaitu mulai dari tingkat kelurahan/desa hingga provinsi 
(Permendagri, 2020). Gerakan PKK dilakukan melalui 10 program pokok meliputi penghayatan dan pengamalan Pancasila, gotong royong, pangan, sandang, perumahan dan tata laksana rumah tangga, pendidikan dan ketrampilan, kesehatan, pengembangan kehidupan berkoperasi, kelestarian lingkungan hidup dan perencanaan sehat (Permendagri, 2020).

Salah satu wilayah yang menerapakan $\begin{array}{lllll}\text { program } & \text { PKK adalah RT 04/RW } & 07\end{array}$ Kelurahan Babat Jerawat, Kecamatan Pakal, Surabaya. Dari hasil observasi, kegiatan PKK yang dilakukan masih monoton yaitu terdiri dari arisan, simpan pinjam, dan acara sosial dan kerohanian. Penerapan program pokok PKK pada butir 3, 5, dan 9 yaitu pangan, pendidikan dan ketrampilan serta kelestarian lingkungan hidup masih kurang optimal. Pada bidang pendidikan, ditunjukkan dengan motivasi yang rendah dari anggota PKK untuk berpartisipasi dalam kegiatan PKK dan masih minimnya pengetahuan dan ketrampilan pada ibu-ibu PKK yang tidak bekerja. Pada bidang pangan, diketahui bahwa belum termanfaatkannya lahan pekarangan dan halaman rumah. Selain itu pada bidang kelestarian lingkungan yang bersih dan sehat, ditemukan jika belum tercipta lingkungan yang bersih dan sehat.
Pemberdayaan pada kaum perempuan merupakan usaha untuk mendorong kaum perempuan untuk meningkatkan kemampuannya. Pemberdayaan ini sangat diperlukan karena dalam kehidupan seharihari perempuan memiliki ruang gerak yang terbatas dalam mengembangkan keterampilan (Herlina, 2019; Supriyadi, 2016).

Dengan adanya permasalahan tersebut, kami ingin melakukan kegiatan pengabdian masyarakat untuk meningkatkan penerapan program pokok PKK terkait pangan, pendidikan dan ketrampilan serta kelestarian lingkungan hidup sehingga tujuan program pokok PKK dalam tercapai.

\section{METODE}

\section{Partisiapan kegiatan}

PKK RT 04/RW 07 Kelurahan Babat Jerawat, Kecamatan Pakal, Surabaya merupakan salah satu wadah organisasi perempuan di RT 04/RW07 Kelurahan Babat Jerawat. PKK RT 04/RW 07 mempunyai 5 (lima) dasawisma yang masing-masing dasawisma mempunyai susunan pengurus yang terdiri dari ketua, sekretaris dan bendahara. Warga yang berdomisili di RT 04/RW 07 sebanyak 52 Kepala Keluarga (KK) dan seluruh istrinya terdaftar sebagai anggota PKK. Kegiatan PKK dilakukan rutin setiap bulan pada minggu kedua di Balai RT 04.

Ekonomi, Sosial, dan Budaya | 937 
Karakteristik masyarakat di RT 04/RW 07 hampir sama yaitu sebagai pegawai pada instansi pemerintah atau swasta, dan ada beberapa yang sudah pensiunan. Anggota PKK hampir 80\% merupakan ibu rumah tangga dan beberapa orang menjadi wirausaha dengan membuka toko di rumah.

\section{Pelaksanaan kegiatan}

Terdapat beberapa metode pelaksanaan kegiatan untuk menyelesaikan permasalahan yang dihadapi yaitu penyuluhan, pelatihan serta pendampingan dan partisipasi mitra. Pertama, dilakukan penyuluhan meliputi: a) Penyuluhan tentang pemahaman tujuan, pengertian, sasaran dan program pokok PKK. Pembinaan ini diharapkan dapat melengkapi wawasan pengetahuan dan keterampilan ibu-ibu PKK dalam berbagai segi kehidupan keluarga, yang dapat digunakan untuk menunjukkan eksistensi dirinya, turut memenuhi kebutuhan keluarganya sehingga dengan melakukan sendiri akan menghemat keuangan keluarga dan dapat dijadikan bekal untuk membuka usaha yang pada akhirnya dapat menambah penghasilan keluarga; b) Penyuluhan tentang pentingnya menjaga kebersihan dan kesehatan lingkungan dengan memanfaatkan pekarangan atau halaman dengan dihiasi tanaman yang memiliki nilai manfaat diantaranya tanaman Toga, Sayur dan Buah dalam pot; c) Penyuluhan peningkatan gizi keluarga. Kedua, pelatihan cara membuat persemaian, pembibitan dan perawatan tanaman Toga, Sayur dan Buah dalam pot. Dengan pelatihan ini dapat menambah ilmu pengetahuan dan wawasan serta kreatifitas ibu-ibu PKK untuk menciptakan lingkungan yang bersih dan sehat dengan pemanfaatan barang bekas seperti kaleng, botol air mineral dan lain sebagainya yang ditata rapi dengan tanaman buah, sayur, maupun toga. Ketiga, pendampingan dan partisipasi mitra. Dalam kegiatan ini tim PPM bersama kader PKK melaksanakan praktek pembibitan, penanaman, perawatan, penataan tanaman serta memanfaatkan barang bekas sehingga dapat menghasilkan manfaat dari tanaman dan mempercantik lingkungan.

\section{HASIL DAN PEMBAHASAN}

Berdasarkan hasil pengamatan, dalam penyelenggaraan program pokok PKK butir 3, 5, dan 9 yaitu pangan, pendidikan dan ketrampilan serta kelestarian lingkungan yang dilaksanakan di RT $04 / \mathrm{RW} \quad 07$ Kelurahan Babat Jerawat, Kecamatan Pakal, Surabaya masih kurang optimal.

Untuk menangani kendala di bidang pendidikan dilakukan penyuluhan berkaitan dengan peran ibu PKK dalam meningkatkan kesejateraan keluarga, pentingnya menjaga kebersihan dan kesehatan lingkungan serta 
peningkatan gizi keluarga. Penyelenggaraan penyuluhan dilaksanakan bersamaan dengan kegiatan pertemuan rutin PKK yang diikuti

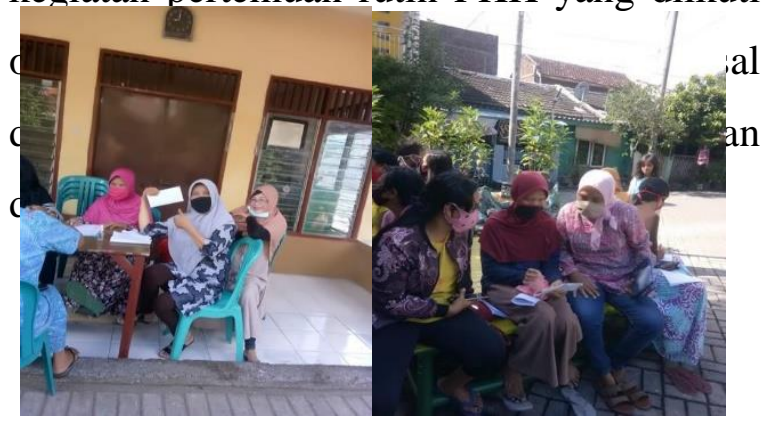

Gambar 1. Penyuluhan PKK

Dalam pelaksanaan penyuluhan tersebut, seluruh peserta memahami peran PKK dalam meningkatkan kesejahteraan keluarga. Dampak dari kegiatan tersebut yaitu meningkatnya kehadiran dan keaktifan seluruh peserta untuk menghadiri kegiatan yang diadakan oleh PKK di RT 04/RW 07 Kelurahan Babat Jerawat, Kecamatan Pakal, Surabaya serta menambah wawasan ibu-ibu PKK.

Untuk mengatasi masalah tentang lahan pekarangan dan halaman rumah yang belum termanfaatkan dengan baik dilakukan pelatihan cara membuat persemaian, pembibitan dan perawatan tanaman Toga, Sayur dan Buah dalam pot; serta pelatihan budidaya lele dalam terpal. Kegiatan tersebut diikuti oleh perwakilan dari masingmasing dasawisma. Hasil dari kegiatan tersebut yaitu terdapat 1 dasawisma yang menjadi percontohan dan terdapat 2 warga yang membudidayakan lele. Dari pelatihan tersebut, ibu-ibu PKK mempraktekkan dengan baik dan berhasil memperoleh hasil buah dan sayur yang ditanam di pekarangan/halam rumah. Selain itu, untuk budidaya lele juga diperoleh hasil yang cukup baik. Berikut merupakan dokumentasi pelaksanaan pelatihan kepada ibu-ibu PKK RT 04/RW 07 :

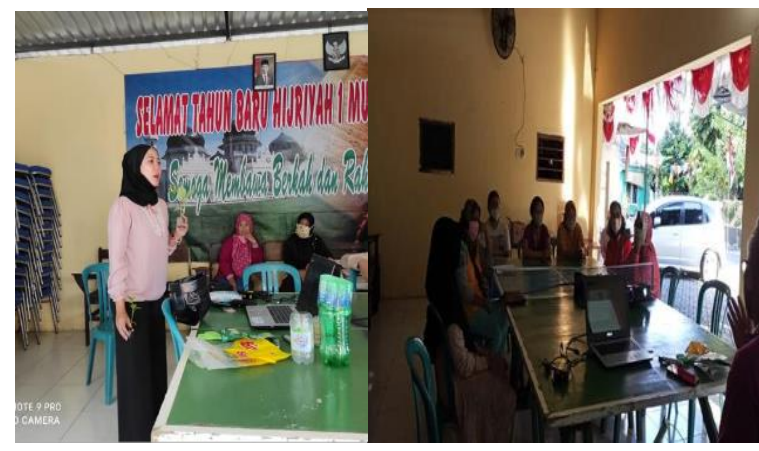

Gambar: Pelatihan Persemaian, Pembibitan dan Perawatan Tanaman

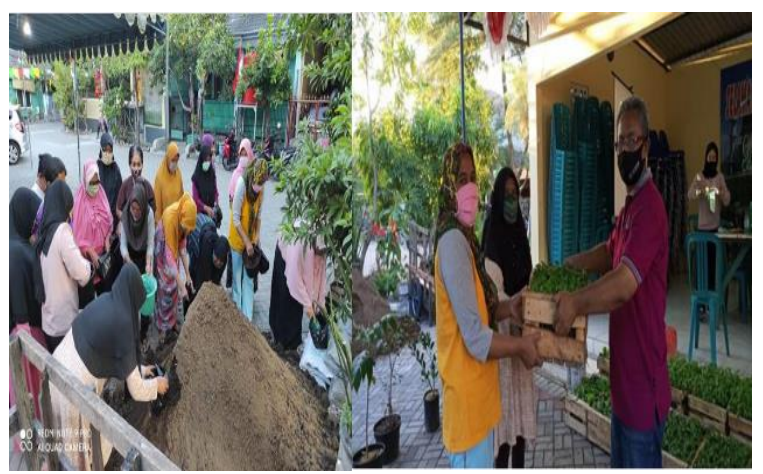

Gambar : Praktek Penanaman Sayur dan Buah

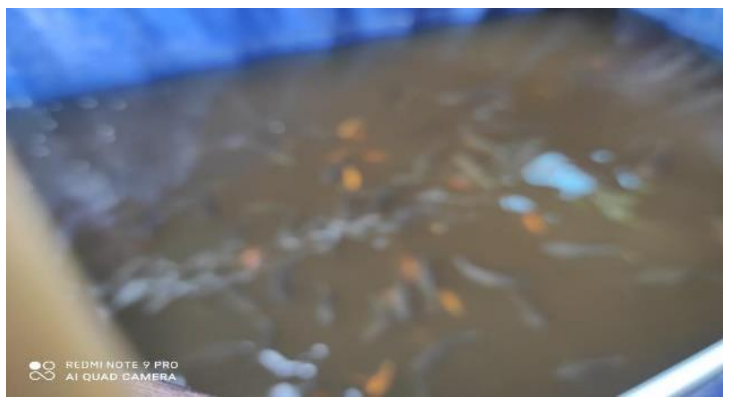

Gambar : Praktek Budidaya Lele

Ekonomi, Sosial, dan Budaya | 939 
Untuk mengatasi dalam menciptakan lingkungan yang bersih dan sehat dilakukan pelatihan pemanfaatan barang bekas. Hasil dari kegiatan tersebut yaitu terdapat 3 rumah warga sebagai percontohan di PKK di RT 04/RW 07 Kelurahan Babat Jerawat, Kecamatan Pakal, Surabaya. Berikut merupakan dokumentasi dari pelaksanaan kegiatan tersebut :

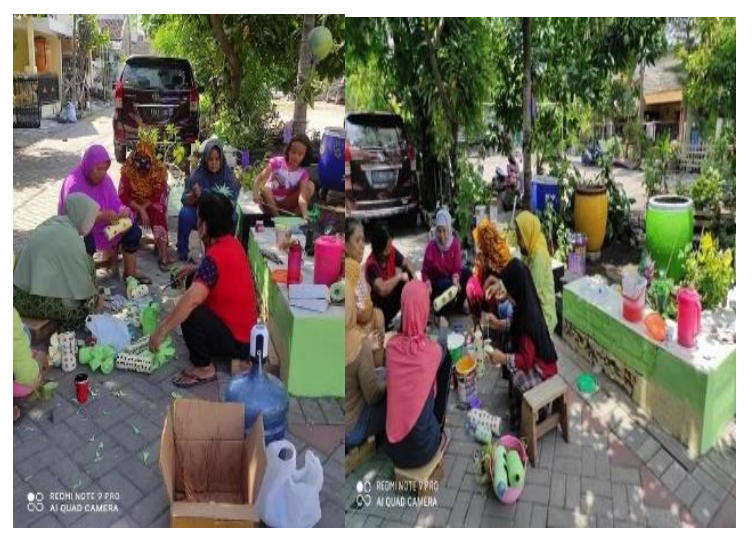

Gambar: Pelatihan Pemanfaatan Barang Bekas

Penyuluhan dan pelatihan yang telah dilakukan dilanjutkan dengan pendampingan. Pendampingan dilakukan mulai dari proses persemaian, pembibitan sampai dengan pertumbuhan tanaman dalam pot. Pendampingan budidaya lele juga dilakukan kepada warga yang telah membudidayakan lele. Demikian juga pemanfaatan barang bekas untuk mempercantik lingkungan rumah. Berikut dokumentasi proses pendampingan yang telah dilakukan :

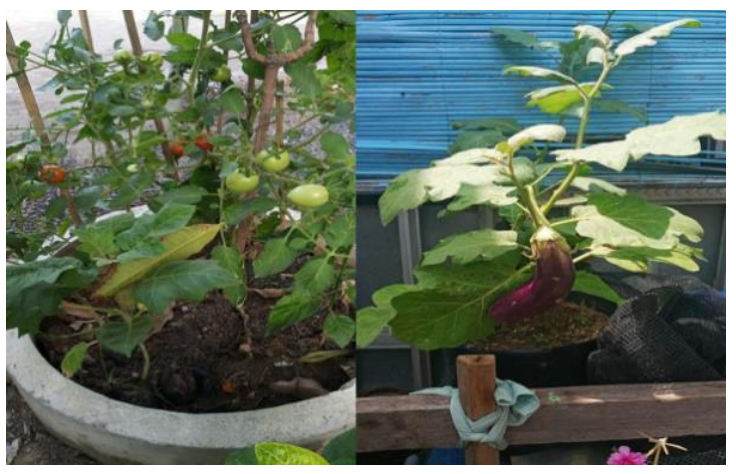

Gambar : Hasil penanaman buah dan sayur

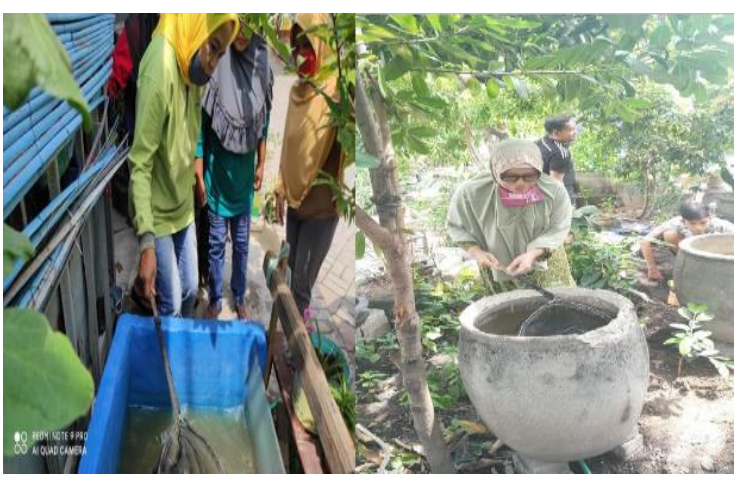

Gambar : Hasil Budidaya Lele

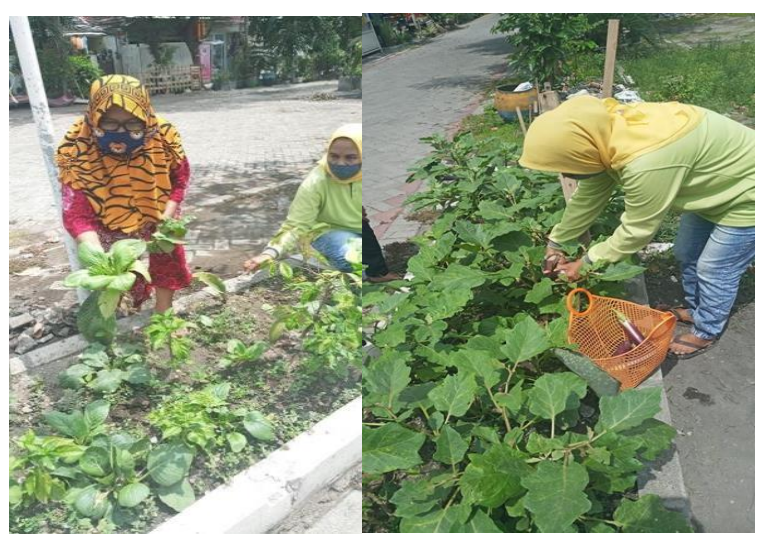

Gambar : Panen sayur dan buah

\section{KESIMPULAN}

Adapun kendala yang ditemukan dalam pelaksanaan kegiatan tersebut yaitu kesibukan ibu-ibu PKK sehingga belum keseluruhan anggota PKK dalam menghadiri kegiatan tersebut. Dengan adanya 
penyuluhan dan pelatihan ini diharapkan untuk kepentingan konsumtif namun perkembangan selanjutnya bisa untuk hasil olahan seperti abon lele serta diadakan bank sampah untuk mengolah bahan bekas yang dapat menghasilkan produk yang bernilai komersil

Berdasarkan hasil pembahasan diatas, maka dapat disimpulkan :

1. Setelah dilakukan penyuluhan, pelatihan dan pendampingan pada ibu PKK Kelurahan Babat Jerawat, Kecamatan Pakal, Surabaya menjadi paham bahwa peran ibu-ibu PKK sangat penting untuk meningkatkan kesejahteraan keluarga.

2. Pemberdayaan ibu-ibu PKK Kelurahan Babat Jerawat, Kecamatan Pakal, Surabaya masih perlu ditingkatkan agar dapat membantu perekonomian keluarga.

3. Pelatihan pemanfaatan barang bekas perlu ditingkatkan agar barang yang dihasilkan dapat bernilai ekonomi hasil budidaya lele bukan hanya

\section{UCAPAN TERIMA KASIH}

Ucapan terima kasih disampaikan kepada Universitas Wijaya Putra, khususnya LPPM yang telah memberikan dukungan dalam pelaksanaan kegiatan.

\section{DAFTAR PUSTAKA}

Permendagri. 2020. Peraturan Menter! Dalam Negeri Republik Indoesia Nomor 36 Tahun 2020 Tentang Peraturan Pelaksanaan Peraturan Presiden Nomor 99 Tahun 2017 Tentang Gerakan Pemberdayaan Dan Kesejahteraan Keluarga.

Supriyadi. 2019. Pemberdayaan Kader PKK Melalui Kegiatan PKK di Desa Banyusidi Kecamatan Pakis Kabupaten Magelang.

Herlena, 2019. Fungsi Pemberdayaan dan Kesejahteraan Keluarga (PKK) dalam Meningkatkan Pemberdayaan Perempuan di Desaa Maasawah Kecamatan Cimerak Kabupaten Pangandaran, Jurnal Moderat:5 hal 201-212. 